\title{
Oxygen for relief of dyspnoea in mildly- or non-hypoxaemic patients with cancer: a systematic review and meta-analysis
}

\author{
HE Uronis ${ }^{1,2}$, DC Currow ${ }^{3}$, DC McCrory ${ }^{4,5}$, GP Samsa ${ }^{5,6}$ and AP Abernethy ${ }^{*, 1,3}$ \\ 'Division of Medical Oncology, Department of Medicine, Duke University Medical Center, Durham, NC, USA; ${ }^{2}$ Health Services Research and \\ Development, Durham Veteran's Affairs Medical Center, Durham, NC, USA; ${ }^{3}$ Department of Palliative and Supportive Services, Division of Medicine, \\ Flinders University, Bedford Park, South Australia, Australia; ${ }^{4}$ Division of General Internal Medicine, Department of Medicine, Duke University Medical \\ Center, Durham, NC, USA; ${ }^{5}$ Center for Clinical Health Policy Research, Duke University Medical Center, Durham, NC, USA; ${ }^{6}$ Department of Biostatistics \\ and Bioinformatics, Duke University, Durham, NC, USA
}

The aim of this study was to determine the efficacy of palliative oxygen for relief of dyspnoea in cancer patients. MEDLINE and EMBASE were searched for randomised controlled trials, comparing oxygen and medical air in cancer patients not qualifying for home oxygen therapy. Abstracts were reviewed and studies were selected using Cochrane methodology. The included studies provided oxygen at rest or during a 6-min walk. The primary outcome was dyspnoea. Standardised mean differences (SMDs) were used to combine scores. Five studies were identified; one was excluded from meta-analysis due to data presentation. Individual patient data were obtained from the authors of the three of the four remaining studies (one each from England, Australia, and the United States). A total of 134 patients were included in the meta-analysis. Oxygen failed to improve dyspnoea in mildly- or non-hypoxaemic cancer patients (SMD $=-0.09,95 \%$ confidence interval -0.22 to $0.04 ; P=0.16$ ). Results were stable to a sensitivity analysis, excluding studies requiring the use of imputed quantities. In this small meta-analysis, oxygen did not provide symptomatic benefit for cancer patients with refractory dyspnoea, who would not normally qualify for home oxygen therapy. Further study of the use of oxygen in this population is warranted given its widespread use.

British Journal of Cancer (2008) 98, 294-299. doi: I0.1038/sj.bjc.6604I6I www.bjcancer.com

Published online 8 January 2008

(c) 2008 Cancer Research UK

Keywords: neoplasms (MeSH); dyspnoea (MeSH); palliative care (MeSH); oxygen (MeSH)

Dyspnoea is common, affecting $50-70 \%$ of patients with advanced cancer (Reuben and Mor, 1986; Ripamonti, 1999; Bruera et al, 2000). Defined by the American Thoracic Society as 'a subjective experience of breathing discomfort that consists of qualitatively distinct sensations that vary in intensity', dyspnoea is a very personal experience (ATS, 1999). Descriptions vary widely; examples include 'short of breath', 'hard to move air', 'chest tightness', 'choking', 'panting', and 'gasping' (Brown et al, 1986; Simon et al, 1989; Roberts et al, 1993; Harver et al, 2000). The experience of dyspnoea can be affected by many conditions, including the cancer itself, coexisting diseases, and cancer cachexia (Reuben and Mor, 1986; Ripamonti, 1999; Bruera et al, 2000). Dyspnoea in cancer survivors has also been correlated with psychological status, including both anxiety and depression (Bruera et al, 2000; Tanaka et al, 2002a), and over 20\% of cancer patients report interference with psychological functioning (Tanaka et al, 2002b).

The sensation cannot always be explained by organic causes (Ahmedzai, 1998; Bruera and Ripamonti, 1998) and is

*Correspondence: Dr AP Abernethy, Division of Medical Oncology, Department of Medicine, Duke University Medical Center, Box 3436, Durham, NC 277I0, USA;

E-mail: amy.abernethy@duke.edu

Received 3 July 2007; accepted 28 November 2007; published online 8 January 2008 influenced by pathways and interactions at multiple levels of the nervous system (Bruera et al, 2000). Dyspnoea appears to be a subjective sensation that is not a direct representation of the intensity of the stimulus in the nervous system but rather the result of an interaction among production, perception, and expression (Ripamonti and Bruera, 1997; Bruera and Ripamonti, 1998).

Management of dyspnoea presents a challenge because there is no roadmap to guide therapy. The typical recommendation is to relieve dyspnoea by treating the underlying cause, but this is often not successful or simply not possible in people with advanced cancer. In these cases, dyspnoea is termed 'refractory' (Abernethy et $a l, 2003$ ) and the focus is on symptom control in an effort to decrease the sensation of dyspnoea. Clinicians choose from a number of palliative interventions, including opioids, psychotropic agents, and nebulised furosemide.

There are data on the role of oxygen in changing survival in hypoxaemic patients $\left(\mathrm{P}_{\mathrm{a}} \mathrm{O}_{2}<55 \mathrm{mmHg}\right)$ with COPD (chronic obstructive pulmonary disease) (NOTTG, 1980; MRCWP, 1981). Data regarding the role of oxygen in relieving the sensation of breathlessness are inconclusive. Evidence for the use of oxygen to relieve the sensation of dyspnoea, the so-called 'palliative oxygen', in patients with malignancy, is also lacking. Despite this, use of palliative oxygen to relieve breathlessness toward the end of life is supported by consensus guidelines (Kvale et al, 2003; Storey and Knight, 2003; Booth et al, 2004) and is a common practice. For example, a recent survey of 648 palliative-care specialists and 
respiratory physicians in Australia and New Zealand demonstrated that palliative oxygen is commonly prescribed with $58 \%$ of 214 respondents reporting a belief that palliative oxygen is beneficial and $65 \%$ reporting that the most common reason for prescribing oxygen was refractory dyspnoea (Abernethy et al, 2005). Canadian physicians report similar practices (Stringer et al, 2004).

The discrepancy between clinical practice and available evidence has several implications. First, patients may be prescribed ineffective treatments. Additionally, oxygen is not a benign intervention. Quality of life may be limited as a result of functional restriction from tubing, tanks, or concentrators; there may be psychological distress in being reliant on a machine (Currow et al, 2007); nasal cannulae might irritate the nose and increase the risk of epistaxis. Home oxygen therapy is also expensive. If patients do not meet funding criteria for home oxygen, they must pay out-ofpocket or receive the intervention on compassionate-use grounds. Funding for home oxygen therapy is a common reason for referral to hospice care. In Canada, about $40 \%$ of patients receiving home oxygen do not meet funding guidelines and receive this intervention on a compassionate-use basis (Guyatt et al, 2000).

In an attempt to improve the understanding of the optimal use of palliative oxygen in patients with malignancy, we conducted a systematic review and meta-analysis aimed at answering the following question: in mildly hypoxaemic or non-hypoxaemic cancer patients with breathlessness, does oxygen therapy improve symptoms?'

\section{METHODS}

\section{Definitions and outcomes}

Oxygen administered by a non-invasive method was defined as oxygen delivered by nasal cannula, mouthpiece, or face mask. Studies that evaluated the effects of oxygen on dyspnoea, either at rest or on exertion, as measured by patient self-report, were sought. Secondary outcomes of interest included quality of life, patient preference, and functional status.

\section{Search strategy}

A general search aimed at identifying articles evaluating the use of oxygen in the context of breathlessness was identified by exploding the MeSH terms dyspnoea, oxygen, and oxygen inhalation therapy and combining them. The text words oxygen, dyspnoea, and breathlessness were also included. The article set generated by this search was then combined with a standard search for randomised controlled trials (Dickersin et al, 1994). The strategies were executed in MEDLINE and EMBASE (from 1966 to December 2006), and were limited to articles involving adult human beings and published in English. Reference lists of included studies and relevant systematic reviews were hand searched.

\section{Literature screening}

Abstracts and full-text versions of articles identified in MEDLINE, EMBASE, and other searches were screened by two investigators (HU and AA) against the following eight exclusion criteria:

- Study design was not a randomised controlled trial;

- Study subjects were not adults with malignancy;

- Study subjects had a mean $\mathrm{P}_{\mathrm{a}} \mathrm{O}_{2}<55 \mathrm{mmHg}$ or more than $50 \%$ of subjects had oxygen saturation $<88 \%$ by pulse oximetry;

- Study subjects were already receiving home oxygen therapy;

- Study intervention was not oxygen vs placebo;

- Method of oxygen delivery was something other than nasal cannula, mouthpiece, or mask;
- No dyspnoea outcomes were reported; and,

- 'Other' reason (e.g., study articles were not editorial or review article).

All abstracts were reviewed by two oncologists (HU and AA) and any article selected by either reviewer was included for full-text review. All full-text articles were reviewed by both oncologists (HU and AA), and the full-text articles meeting all inclusion criteria were selected for full abstraction. Differences in judgment were resolved by consensus conference.

\section{Data abstraction}

For each article meeting the inclusion criteria, basic study parameters were abstracted into evidence tables summarising the following: study design, primary focus, inclusion/exclusion criteria, interventions and how administered, subjects, outcomes, results, and quality assessment. Abstractions were performed by one investigator (HU) and were over-read by a second investigator (AA) to ensure accuracy.

\section{Quality assessment}

Studies were assessed for both internal and external validity. Internal validity criteria included randomisation, blinding, and description of withdrawals/dropouts, and each study was assigned a Jadad score (Jadad et al, 1996). External validity criteria included subject description, detailed intervention description, and adequately reported dyspnoea outcomes.

\section{Data analysis}

Dyspnoea ratings measured by modified Borg, 0-10 numerical rating scale (NRS), $100 \mathrm{~mm}$ visual analog scale (VAS), or $300 \mathrm{~mm}$ VAS were converted into standardised mean differences (SMDs). Results of both periods of crossover trials were used. Crossover trials should be included in meta-analyses using results from paired analyses. However, these data are often not available. In these cases, standard errors were estimated using methods described by Follmann et al (1992). Correlations between repeated outcomes were estimated from $P$-values when available and, when unavailable, the lowest estimate from other studies was used.

Statistical analyses, except meta-analyses, were conducted using SAS E-Guide version 3 for Windows (SAS Institute, Cary, NC, USA). Meta-analyses were conducted for those studies where means and variances for dyspnoea measurements could be estimated from published reports. Authors were contacted for additional data if published information was not sufficient. For meta-analyses, effect sizes were calculated using Cochrane software, RevMan 4.2.8., and are reported as SMD with 95\% confidence intervals (CIs). Two-sided $P$-values are reported and statistical significance was assumed if $P<0.05$ (Supplementary Information).

\section{RESULTS}

\section{Article review}

The flow of articles reviewed is presented in Figure 1. This study on cancer was conducted in conjunction with a second review that focused on COPD and other aetiologies of breathlessness. Studies that did not include cancer patients were excluded from this analysis. The five abstracted articles represent data from five different studies (Table 1; Bruera et al, 1993, 2003; Booth et al, 1996; Ahmedzai et al, 2004; Philip et al, 2006). 


\section{Study characteristics}

Design characteristics All five studies included in this analysis were blinded, randomised, and controlled crossover trials. In this type of trial, participants are assigned to study arms consisting of two or more treatments given consecutively and in random order (Sibbald and Roberts, 1998). Each subject acts as his/her own control, so that the response to treatment A can be compared with that of treatment B without concern for issues involving patient variation, if the duration of therapy in each arm means that the other factors affecting the symptom are likely to remain stable for the entire study. Crossover trials are commonly used in palliativecare research given the ability to directly compare two treatments in the same patient and the ability to answer a clinical question with fewer subjects than is required in a traditional parallel group trial. As is typical for palliative-care studies, sample sizes in the five studies included were small with a median of 33 participants per study and a mean of 29.6 (s.d. 16.5). None of the studies

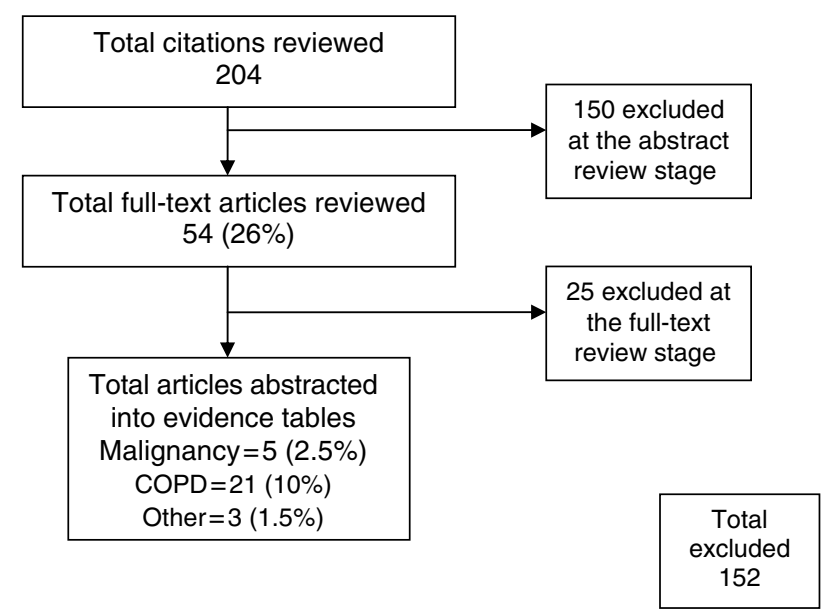

Figure I Flowchart of articles reviewed for the systematic analysis of the benefit of palliative oxygen for the relief of dyspnoea in people with cancer who do not qualify for long-term domiciliary oxygen therapy. included had evidence of calculations required to claim adequate power to answer the questions.

Patient characteristics The five included studies represented 148 participants, all of them adults. Median participant age was 65 and $39 \%$ were females; no information was available on race or ethnicity. Participants had several different types of malignancy, with lung cancer $(65 \%)$ or unspecified cancer with metastasis to the lung (15\%) being most common. The profile of other malignancies was as follows: breast (5\%), colon (3\%), and others, including lymphoma, melanoma, sarcoma, carcinoid, skin, bladder, and head and neck (7\%). Baseline percent oxygen saturation that was provided by four out of five studies are as follows: median $93 \%$ (Philip et al, 2006), median 94\% (Ahmedzai et al, 2004), median 98\% (Bruera et al, 2003), and range 80-99\% (Booth et al, 1996). Baseline dyspnoea at rest that was provided in three out of five studies are as follows: $0 \mathrm{~mm}$ by modified Borg (Ahmedzai et al, 2004), $5 \mathrm{~mm}$ by NRS (Bruera et al, 2003), and $59 \mathrm{~mm}$ by $100 \mathrm{~mm}$ VAS (Booth et al, 1996).

Intervention characteristics Four studies (Bruera et al, 1993, 2003; Booth et al, 1996; Philip et al, 2006) were focused on evaluating oxygen $v s$ medical air for relief of dyspnoea, whereas the fourth evaluated the use of Heliox 28 , a novel agent containing $72 \%$ helium and $28 \%$ oxygen $v$ s oxygen and medical air (Ahmedzai et al, 2004). Oxygen was delivered by nasal canula in three studies (Booth et al, 1996; Bruera et al, 2003; Philip et al, 2006) and by mask in two (Bruera et al, 1993; Ahmedzai et al, 2004); doses of oxygen ranged from 3 to $51 \mathrm{~min}^{-1}$. Oxygen was administered at rest in three studies (Bruera et al, 1993; Booth et al, 1996; Philip et al, 2006) and during a 6MWT (6-min walk test) in two studies (Bruera et al, 2003; Ahmedzai et al, 2004).

\section{Treatment efficacy}

Estimation of treatment efficacy Overall, the quality of reporting was poor with four out of five studies having a Jadad score of 2, indicating inadequate discussion of methods of both randomisation and blinding (Jadad et al, 1996). Only one out of five studies provided sufficient information to calculate SMD and variances for

Table I Characteristics of included studies exploring the role of oxygen therapy in people with refractory dyspnoea who do not qualify for long-term oxygen therapy

\begin{tabular}{|c|c|c|c|c|c|c|c|}
\hline Reference & $n$ & Population & $\begin{array}{l}\mathrm{O}_{2} \text { saturation } \\
<90 \% \text { included? }\end{array}$ & Intervention & $\begin{array}{l}\text { Outcome } \\
\text { measure }\end{array}$ & Results & Quality $^{\mathbf{a}}$ \\
\hline (Philip et al, 2006) & 51 & $\begin{array}{l}\text { Cancer of any type, } \\
\text { dyspnoea }\end{array}$ & Yes 17 (33\%) & $\begin{array}{l}\text { CA vs } \mathrm{O}_{2}, 41 \mathrm{~min}^{-1} \\
\text { at rest }\end{array}$ & $100 \mathrm{~mm}$ VAS & $\begin{array}{l}\text { No significant } \\
\text { difference in dyspnoea } \\
\text { with } \mathrm{O}_{2} \text { vs CA }\end{array}$ & 2 \\
\hline $\begin{array}{l}\text { (Ahmedzai et al, 1998, } \\
\text { 2004) }\end{array}$ & 12 & $\begin{array}{l}\text { Lung cancer, dyspnoea } \\
\text { on exertion }\end{array}$ & No & $\begin{array}{l}\mathrm{CA} \text { vs } \mathrm{O}_{2}, 8-101 \mathrm{~min}^{-1} \\
\text { during } 6 \mathrm{MWT}\end{array}$ & $\begin{array}{l}\text { Modified Borg and } \\
100 \mathrm{~mm} \text { VAS }\end{array}$ & $\begin{array}{l}\text { No significant } \\
\text { difference in dyspnoea } \\
\text { with } \mathrm{O}_{2} \text { vs CA }\end{array}$ & 2 \\
\hline (Booth et al, 1996, 2004) & 38 & $\begin{array}{l}\text { Advanced cancer of } \\
\text { any type, dyspnoea at } \\
\text { rest }\end{array}$ & Yes 6 (16\%) & $\begin{array}{l}\mathrm{CA} \text { vs } \mathrm{O}_{2}, 41 \mathrm{~min}^{-1} \\
\text { at rest }\end{array}$ & $\begin{array}{l}\text { Modified Borg and } \\
100 \mathrm{~mm} \text { VAS }\end{array}$ & $\begin{array}{l}\text { No significant } \\
\text { difference in dyspnoea } \\
\text { with } \mathrm{O}_{2} \text { vs CA }\end{array}$ & 2 \\
\hline (Bruera et al, 1993) & 14 & $\begin{array}{l}\text { Advanced cancer of } \\
\text { any type, dyspnoea, } \\
\text { oxygen saturation } \\
<90 \%\end{array}$ & Yes 14 (100\%) & $\begin{array}{l}\mathrm{CA} \text { vs } \mathrm{O}_{2} 51 \mathrm{~min}^{-1} \\
\text { at rest }\end{array}$ & NRS & $\begin{array}{l}\text { Significant } \\
\text { improvement in } \\
\text { dyspnoea with } \mathrm{O}_{2} \text { vs } \\
\text { CA }\end{array}$ & 2 \\
\hline
\end{tabular}

Abbreviations: $\mathrm{CA}=$ compressed air; $\mathrm{O}_{2}=$ oxygen; $6 \mathrm{MWT}=6$-min walk test; $\mathrm{VAS}=$ visual analog scale; NRS = numerical rating scale. ${ }^{\mathrm{a}} \mathrm{Quality}$ as assessed by Jadad score (Jadad et al, 1996). 


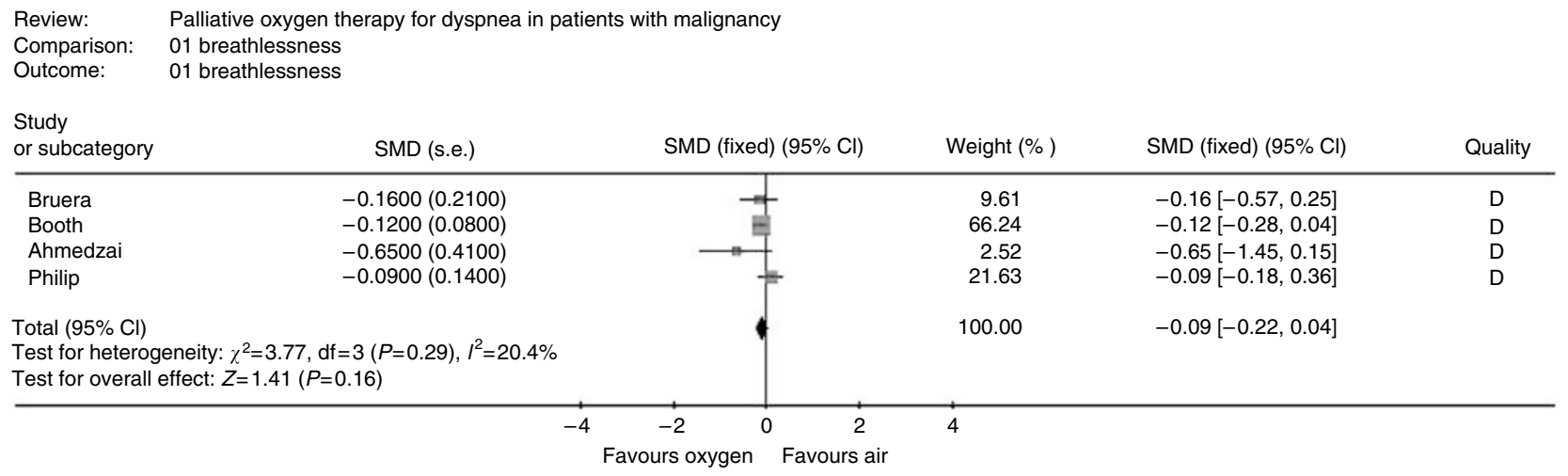

Figure 2 Estimation of efficacy of oxygen in the treatment of dyspnoea in cancer patients who do not qualify for long-term domiciliary oxygen therapy.

\begin{tabular}{l}
$\begin{array}{l}\text { Review: } \\
\text { Comparison: }\end{array} \begin{array}{l}\text { Palliative oxygen therapy for dyspnea in patients with malignancy } \\
01 \text { breathlessness } \\
\text { Outcome: }\end{array}$ \\
$\begin{array}{l}\text { Study breathlessness no imputed quantities } \\
\text { or subcategory }\end{array}$ \\
\hline SMD (s.e.)
\end{tabular}

Figure 3 Sensitivity analysis of blinded, randomised controlled trials exploring the symptomatic benefit of oxygen therapy in reducing refractory dyspnoea in a palliative population which does not qualify for domiciliary oxygen - no studies requiring use of imputed quantities.

dyspnoea measurements. As a result, all the authors were contacted to request individual patient data. All the authors responded; individual patient data were available for three studies (Booth et al, 1996; Bruera et al, 2003; Philip et al, 2006) and were unavailable for the other two (Bruera et al, 1993; Ahmedzai et al, 2004). Using correlations calculated from available data, it was possible to derive s.e. for a fourth study (Ahmedzai et al, 2004). The remaining study (Bruera et al, 1993) was excluded from meta-analysis, leaving 134 patients included. Oxygen failed to improve dyspnoea in mildly- or non-hypoxaemic cancer patients $(\mathrm{SMD}=-0.09,95 \% \mathrm{CI}-0.22$ to $0.04 ; P=0.16$ ) (Figure 2). This finding is consistent with a global assessment reflecting that four out of five individual studies were negative. Sensitivity analysis excluding the study requiring the use of imputed quantities was performed; results were stable in this analysis (Figure 3).

Other outcomes Two out of five included studies also reported the impact of oxygen on results of the distance walked during the 6MWT (Bruera et al, 2003; Ahmedzai et al, 2004). One study reported a statistically significant increase in the distance with the use of oxygen (174.6 m (s.d. 11.2)) vs medical air (128.8 m (s.d. 10.3)) $(P<0.01)$ (Ahmedzai et al, 2004). However, a second study reported no difference in distance with oxygen (331.6 m (s.d. 54.9)) and with medical air (330.7 (s.d. 57.6)) (Bruera et al, 2003). Four out of five studies reported results of still-blinded patient preference for oxygen vs medical air. Two out of four studies reported a statistically significant still-blinded patient preference for oxygen $v s$ air, whereas the other two found no such difference (Table 2).

\section{DISCUSSION}

Oxygen was not effective at reducing the sensation of dyspnoea in cancer patients who would not otherwise qualify for home oxygen therapy, with an SMD $=-0.09$ (95\% CI: -0.22 to 0.04 ; $P=0.16)$ translating into a $0.19-\mathrm{cm}$ reduction in dyspnoea on a $10 \mathrm{~cm}$ VAS or a 0.22 -point reduction in dyspnoea on a $0-10$ NRS. When evaluating interventions for dyspnoea, most clinicians would consider a change of $10 \mathrm{~cm}$ on a $10 \mathrm{~cm}$ VAS or a 1-point reduction on a $0-10$ NRS to be clinically significant. So, the observed reduction does not represent a clinically significant change.

Two out of five studies evaluated the impact of oxygen on exercise tolerance by evaluating patients during a 6MWT conducted either with oxygen or medical air. The results were conflicting with one study finding a clinically and statistically significant improvement in distance walked with oxygen as opposed to air and the other failing to do so. Why might this be the case? It is not immediately clear because the two populations were very similar. In the study by Bruera et al (2003), median age was 64 years, $64 \%$ were male, $94 \%$ had primary lung cancer, median baseline oxygen saturation was $98 \%$, and median usual dyspnoea on activity (as measured by $0-10$ NRS) was 5 . In the study by Ahmedzai et al (2004), median age was 72.5 years, $58 \%$ 
Table 2 Blinded patient preference in the four randomised controlled studies that were assessing the role of oxygen in relieving refractory dyspnoea in people who currently do not qualify for long-term domiciliary oxygen therapy

\begin{tabular}{|c|c|c|c|}
\hline Reference & n & Population & Patient preference \\
\hline (Philip et al, 2006) & 51 & Cancer of any type, dyspnoea & $\begin{array}{l}\text { Preference for oxygen }=2 \mid(4 \mid \%) \\
\text { Preference for air }=15(29 \%) \\
\text { No preference }=15(29 \%)\end{array}$ \\
\hline (Ahmedzai et al, 1998, 2004) & 12 & Lung cancer, dyspnoea on exertion & Not reported \\
\hline (Bruera et al, 2003) & 33 & $\begin{array}{l}\text { Advanced cancer of any type, dyspnoea at rest or } \\
\text { on mild exertion }\end{array}$ & $\begin{array}{l}\text { Preference for oxygen }=19(58 \%)^{\mathrm{a}} \\
\text { Preference for air }=1 \mid(33 \%)^{\mathrm{a}} \\
\text { No preference }=3(9 \%)\end{array}$ \\
\hline (Booth et al, 1996, 2004) & 38 & Advanced cancer of any type, dyspnoea at rest & $\begin{array}{l}\text { Preference for oxygen }=15(54 \%)^{b} \\
\text { Preference for air }=11(39 \%)^{b} \\
\text { Worse with oxygen }=2(7 \%)^{b} \\
\text { Worse with air = } 3(11 \%)^{b}\end{array}$ \\
\hline (Bruera et al, 1993) & 14 & $\begin{array}{l}\text { Advanced cancer of any type, dyspnoea, oxygen } \\
\text { saturation }<90 \%\end{array}$ & $\begin{array}{l}\text { Preference for oxygen }=12(86 \%)^{c} \\
\text { Preference for air }=1(7 \%)^{c} \\
\text { No preference }=1(7 \%)^{c}\end{array}$ \\
\hline
\end{tabular}

${ }^{\mathrm{a}} P<0.05$ for comparison. ${ }^{\mathrm{b}}$ Based only on those who made some comment $(n=28) .{ }^{\mathrm{C} P}<0.00 \mathrm{I}$ for comparison.

were male, $100 \%$ had primary lung cancer, median baseline oxygen saturation was 94\%, and median dyspnoea on exertion (as measured by modified Borg) was 3 . The similarities between the two samples suggest that the conflicting results are likely due to chance and that further study is warranted.

Patient preference was also discussed in two out of four studies. This is known to be important as the COPD literature has demonstrated that even patients shown to get benefited from oxygen do not always wish to receive it (Eaton et al, 2002; Currow et al, 2007). It is also a critical issue given the subjective nature of dyspnoea and the fact that patients often have difficulty in describing the sensation (ATS, 1999). Unfortunately, the data on patient preference are not definitive, with only two out of four studies demonstrating statistically significant patient preference for oxygen. Again, the reason for this lack of agreement is not clear, but it may be a result of small sample size and/or relative heterogeneity in the study population. Interestingly, one of the studies reporting a significant patient preference for oxygen (Bruera et al, 2003) failed to find a statistically significant improvement in dyspnoea as measured by the $0-10$ NRS. This may reflect the subjective nature of dyspnoea as well as the difficulties in measuring the sensation, particularly in cancer patients.

Our systematic review does have several strengths. First, the search was conducted in both MEDLINE and EMBASE, allowing incorporation of a broad range of publications and increasing our ability to identify articles addressing this specific question. Second, we contacted the authors of the included studies for additional data. All responded and individual patient data were subsequently available for an additional three studies, significantly strengthening our meta-analysis. Third, we followed Cochrane methodology for study review, data abstraction, and data analysis.

In addition to the inherent issues associated with the current body of literature evaluating the optimal use of oxygen in dyspnoeic cancer patients who did not qualify for the home oxygen therapy, there are several limitations specific to our review. First, patients were included in each of the studies based on oxygen saturation as measured by pulse oximetry, a reasonably accurate way of evaluating oxygenation but one that is affected by a number of physiologic variables, including haemoglobin level, 2,3-diphos- phoglycerate levels, arterial blood flow, temperature of the digit where the oximeter is located, skin pigmentation, and motion artifact (Jensen et al, 1998). Although direct measurement of arterial oxygen saturation by arterial blood gas analysis would be preferable, the use of pulse oximetry is not surprising given that these studies were performed in a palliative-care population where invasive testing is typically minimised. Second, the patient population represents a mixture of individuals with oxygen saturations both above and below $90 \%$ by pulse oximetry. While we set out to exclude studies evaluating patients who were clearly hypoxaemic $\left(\mathrm{P}_{\mathrm{a}} \mathrm{O}_{2}<55 \mathrm{mmHg}\right)$, it became clear that this would not be possible due to the lack of arterial blood gas data. We attempted to decrease the impact on our analysis by excluding those studies where more than $50 \%$ of participants had a baseline oxygen saturation of $<90 \%$ (roughly equivalent to a $\mathrm{P}_{\mathrm{a}} \mathrm{O}_{2}$ of $60 \mathrm{mmHg}$ using the oxyhaemoglobin dissociation curve) from meta-analysis; no studies meeting this criterion were identified. As a result, we may have included individuals with $\mathrm{P}_{\mathrm{a}} \mathrm{O}_{2}<55 \mathrm{mmHg}$ and/or excluded individuals with $\mathrm{P}_{\mathrm{a}} \mathrm{O}_{2}=55-59 \mathrm{mmHg}$. Both scenarios could certainly impact our analysis although there are no available data to suggest the direction in which that impact would be seen. Third, the sample size was small $(n=148)$ and $65 \%$ of patients carried a diagnosis of lung cancer. This limits the generalizability of these results to a population of patients with a wider range of malignancies given the number of factors that contribute to dyspnoea in this population.

In summary, available data do not provide support for the use of palliative oxygen for relief of the sensation of refractory dyspnoea in cancer patients. However, limitations in the data make it difficult to come to firm conclusions on such an important issue as evidenced by the fact that clinicians across the globe continue to prescribe oxygen for refractory dyspnoea (Abernethy et al, 2005). The data on patient preference, obtained when patients were stillblinded to the intervention, suggest that there is a population of patients who experience less dyspnoea while receiving oxygen as compared with medical air. Further research is required to appropriately identify these subgroups of people. Until such data are available, decisions regarding the use of palliative oxygen can be made on an individual basis after an ' $n$ of 1 ' assessment as described by Bruera et al (1992). 


\section{ACKNOWLEDGEMENTS}

We thank Dr Sara Booth, Dr Eduardo Bruera, and Dr Odette Spruyt for their willingness to provide us with individual patient data for our analysis. We also thank Ms Anne Powers (Duke University Medical Center Library) for her help in designing the search strategy and Ms Belinda Fazekas (Repatriation General Hospital, Daw Park, South Australia) for her help in executing our

\section{REFERENCES}

Abernethy AP, Currow DC, Frith P, Fazekas B (2005) Prescribing palliative oxygen: a clinician survey of expected benefit and patterns of use. Palliat Med 19: $168-170$

Abernethy AP, Currow DC, Frith P, Fazekas BS, McHugh A, Bui C (2003) Randomised, double blind, placebo controlled crossover trial of sustained release morphine for the management of refractory dyspnoea. BMJ 327: $523-528$

Ahmedzai S (1998) Palliation of respiratory symptoms. In: Oxford Textbook of Palliative Medicine, Doyle D, Hanks G, MacDonald N (eds) pp 583616. Oxford: Oxford University Press

Ahmedzai SH, Laude E, Robertson A, Troy G, Vora V (2004) A doubleblind, randomised, controlled phase II trial of Heliox 28 gas mixture in lung cancer patients with dyspnoea on exertion. Br J Cancer 90: 366-371

ATS (1999) Dyspnoea. Mechanisms, assessment, and management: a consensus statement. American Thoracic Society. Am J Respir Crit Care Med 159: $321-340$

Booth S, Kelly MJ, Cox NP, Adams L, Guz A (1996) Does oxygen help dyspnoea in patients with cancer? Am J Respir Crit Care Med 153: 1515- 1518

Booth S, Wade R, Johnson M, Kite S, Swannick M, Anderson H (2004) The use of oxygen in the palliation of breathlessness. A report of the expert working group of the Scientific Committee of the Association of Palliative Medicine. Respir Med 98: 66-77

Brown ML, Carrieri V, Janson B, Dodd MJ (1986) Lung cancer and dyspnoea: the patient's perception. Oncol Nurs Forum 13: 19-24

Bruera E, de Stoutz N, Velasco-Leiva A, Schoeller T, Hanson J (1993) Effects of oxygen on dyspnoea in hypoxaemic terminal-cancer patients. Lancet 342: $13-14$

Bruera E, Ripamonti C (1998) Dyspnoea in patients with advanced cancer. In: Principles and practice of supportive oncology, Berger A, Portenoy R, Weissman D (eds) pp 295-308. Philadelphia: Lippencott-Raven Publishers

Bruera E, Schmitz B, Pither J, Neumann CM, Hanson J (2000) The frequency and correlates of dyspnoea in patients with advanced cancer. J Pain Symptom Manage 19: 357-362

Bruera E, Schoeller T, MacEachern T (1992) Symptomatic benefit of supplemental oxygen in hypoxemic patients with terminal cancer: the use of the $N$ of 1 randomized controlled trial. J Pain Symptom Manage 7: $365-368$

Bruera E, Sweeney C, Willey J, Palmer JL, Strasser F, Morice RC, Pisters K (2003) A randomized controlled trial of supplemental oxygen $v s$ air in cancer patients with dyspnoea. Palliat Med 17: 659-663

Currow DC, Fazekas B, Abernethy AP (2007) Oxygen use-patients define symptomatic benefit discerningly. J Pain Symptom Manage 34: 113-114

Dickersin K, Scherer R, Lefebvre C (1994) Identifying relevant studies for systematic reviews. BMJ 309: 1286-1291

Eaton T, Garrett JE, Young P, Fergusson W, Kolbe J, Rudkin S, Whyte K (2002) Ambulatory oxygen improves quality of life of COPD patients: a randomised controlled study. Eur Respir J 20: 306-312

Follmann D, Elliott P, Suh I, Cutler J (1992) Variance imputation for overviews of clinical trials with continuous response. J Clin Epidemiol 45: $769-773$ search in EMBASE. Dr Uronis' salary is generously supported by the Agency for Healthcare Research and Quality (Grant number 5 T32 HS000079).

Supplementary Information accompanies the paper on British Journal of Cancer website (http://www.nature.com/bjc)

Guyatt GH, McKim DA, Austin P, Bryan R, Norgren J, Weaver B, Goldstein RS (2000) Appropriateness of domiciliary oxygen delivery. Chest 118: $1303-1308$

Harver A, Mahler DA, Schwartzstein RM, Baird JC (2000) Descriptors of breathlessness in healthy individuals: distinct and separable constructs. Chest 118: $679-690$

Jadad AR, Moore RA, Carroll D, Jenkinson C, Reynolds DJ, Gavaghan DJ, McQuay HJ (1996) Assessing the quality of reports of randomized clinical trials: is blinding necessary? Control Clin Trials 17: 1-12

Jensen LA, Onyskiw JE, Prasad NG (1998) Meta-analysis of arterial oxygen saturation monitoring by pulse oximetry in adults. Heart Lung 27: $387-408$

Kvale PA, Simoff M, Prakash UB (2003) Lung cancer. Palliative care. Chest 123: $284 \mathrm{~S}-311 \mathrm{~S}$

MRCWP (1981) Long term domiciliary oxygen therapy in chronic hypoxic cor pulmonale complicating chronic bronchitis and emphysema. Report of the Medical Research Council Working Party. Lancet 1: 681-686

NOTTG (1980) Continuous or nocturnal oxygen therapy in hypoxemic chronic obstructive lung disease: a clinical trial. Nocturnal Oxygen Therapy Trial Group. Ann Intern Med 93: 391 - 398

Philip J, Gold M, Milner A, Di Iulio J, Miller B, Spruyt O (2006) A randomized, double-blind, crossover trial of the effect of oxygen on dyspnoea in patients with advanced cancer. J Pain Symptom Manage 32: $541-550$

Reuben DB, Mor V (1986) Dyspnoea in terminally ill cancer patients. Chest 89: $234-236$

Ripamonti C, Bruera E (1997) Dyspnoea: pathophysiology and assessment. J Pain Symptom Manage 13: 220-232

Ripamonti C (1999) Management of dyspnoea in advanced cancer patients. Support Care Cancer 7: 233-243

Roberts DK, Thorne SE, Pearson C (1993) The experience of dyspnoea in late-stage cancer. Patients' and nurses' perspectives. Cancer Nurs 16: $310-320$

Sibbald B, Roberts C (1998) Understanding controlled trials. Crossover trials. $B M J$ 316: 1719

Simon PM, Schwartzstein RM, Weiss JW, Lahive K, Fencl V, Teghtsoonian M, Weinberger SE (1989) Distinguishable sensations of breathlessness induced in normal volunteers. Am Rev Respir Dis 140: 1021-1027

Storey P, Knight CF (2003) UNIPAC Four: Management of Selected NonPain Symptoms in the Terminally Ill, Vol. 83 Glenview, IL: American Academy of Hospice and Palliative Medicine

Stringer E, McParland C, Hernandez P (2004) Physician practices for prescribing supplemental oxygen in the palliative care setting. J Palliat Care 20: $303-307$

Tanaka K, Akechi T, Okuyama T, Nishiwaki Y, Uchitomi Y (2002a) Factors correlated with dyspnoea in advanced lung cancer patients: organic causes and what else? J Pain Symptom Manage 23: 490-500

Tanaka K, Akechi T, Okuyama T, Nishiwaki Y, Uchitomi Y (2002b) Prevalence and screening of dyspnoea interfering with daily life activities in ambulatory patients with advanced lung cancer. J Pain Symptom Manage 23: $484-489$ 